\title{
Longitudinal Study on Relationships among Snack Energy Intake, Body Mass Index, and Nutrient Intake in Japanese Children Aged 6-7 Years
}

\author{
Toshiyuki KoHri ${ }^{1}$, Ayato SHIMIZU ${ }^{2}$, Taro SuzUKI ${ }^{3}$, Kimiko RYU² ${ }^{2}$ Natsuko IGUCHI ${ }^{2}$, \\ Chiho MYoJIN ${ }^{2}$, Masako KAWANISHI ${ }^{2}$ and Hiroyuki TOMOTAKE ${ }^{4}$ \\ ${ }^{1}$ Department of Clinical Nutrition and Dietetics, Faculty of Clinical Nutrition and Dietetics, Konan \\ Women's University, 6-2-23 Morikita-machi, Higashinada-ku, Kobe 658-0001, Japan \\ ${ }^{2}$ Department of Food and Nutrition, Faculty of Agriculture, Kindai University, \\ 3327-204 Nakamachi, Nara 631-8505, Japan \\ ${ }^{3}$ The Center for Data Science Education and Research, Shiga University, \\ 1-1-1 Banba, Hikone, Shiga 552-8522, Japan \\ ${ }^{4}$ Department of Domestic Science, Iida Women's Junior College, 610 Matsuoshiroda, Iida 395-0812, Japan
}

(Received September 21, 2020)

\begin{abstract}
Summary A longitudinal study was conducted to assess associations between snack energy intake and either body mass index (BMI) or nutrient intake in Japanese children. A baseline survey was conducted with 243 children aged 6-7 y, and follow-up was performed 4 y later. Finally, 189 subjects were selected for the analysis. Snack intakes were obtained from self-administered records by guardians. The daily habitual whole dietary intake and exercise/sleep hours were obtained by questionnaires during the follow-up. Subjects were grouped into three, as per snack energy intake tertiles at baseline. Differences and linear trends between the three groups were tested for the mean values of snack energy intake, BMI, and nutrient density, 4 y after the baseline survey. In follow-up, the snack energy intake (kcal) in females was significantly higher in the intermediate $(335 \pm 35, p<0.01)$ and high $(318 \pm 32, p<0.05)$ groups than in low group $(196 \pm 25)$. There was no significant difference in follow-up BMI in the three groups. However, after adjustment of the baseline BMI, a significantly positive linear trend $(p<0.05)$ was observed in the follow-up BMI in females. There was no significant difference in total energy intake per day. In contrast, a significantly negative linear trend $(p<0.05)$ was observed among the three groups in dietary nutrient density of calcium and vitamin A in females. These results suggest that, in females, a higher intake of snacks may affect the daily dietary balance, resulting in a higher BMI and lower mineral and vitamin intakes.
\end{abstract}

Key Words diet, BMI, obesity, obese, confectionery, sweets, candy, nutrition, child, children

Snacks are types of food that are of great interest to children (1). Snacking plays the role of supplementing energy and nutrients that a small child lacks from just having three meals, and contributes to the emotional stability, including mood change (2). However, there are concerns about obesity and the deterioration of eating habits due to the excessive consumption of snacks and soft drinks (3). Eating habits during childhood are associated with the eating habits and lifestyle-related diseases after the age of $20 \mathrm{y}$ (4). In the United States, simulation result revealed that about half of the obese children will develop adult obesity (5), which suggests the importance of eating habits in children. In the 20112014 snack survey in the United States, children aged 6-11 y consumed an average of $469 \mathrm{kcal}$ per day of snacks (6). Snack intake has been increasing worldwide and has become a food with a great influence on the eating habits in children (7). Nevertheless, it is not clear

E-mail: tkohri@konan-wu.ac.jp whether snacking is necessary and healthy for children.

Therefore, there is an interest to study the relationship between snacking and obesity in children, and in fact, there are many reports on the relationship between snacking and body mass index (BMI) in children. However, while reports exist that snacking increases obesity $(8-10)$, another study indicated no relationship (11) between snacking and obesity. In addition, some reports suggested that one becomes thinner by eating snacks $(12,13)$; therefore, the evidence on the relationship between snacking and BMI in children is not consistent. One reason for this inconsistency is that most of the research designs were cross-sectional. As observed in a cross-sectional study, obese children may temporarily refrain from snacking, or conversely, lean children may temporarily eat more snacks to replenish their energy. Therefore, the relationship between cause and effect may be distorted. For this reason, short duration interventional studies have been reported, in which a small number of subjects eat different types of snacks, during 
different timings of ingestion (whether it is free or between meals); although the findings revealed inconsistent results (14). Interventional studies are difficult to conduct in children; so, longitudinal studies are useful, but only few have been conducted $(15,16)$. Previous studies have often investigated the relationship between the frequency of snack intake and BMI. In such studies, the portion size of the snack was not constant, and the type of snack was unknown. Therefore, the energy intake of the snacks was unknown; and, the results may vary. Another factor is the ambiguous definition of snacks $(17,18)$; in the present study, snacks were defined as all the foods or drinks consumed between the main meals.

The main purpose of this study was to examine the relationship between snack energy intake and BMI in children for $4 \mathrm{y}$. Snack energy intake in children was obtained by guardians' self-administered snack record survey. The children were divided into three groups based on the tertiles of the snacking energy intake at the baseline survey, and $4 \mathrm{y}$ later, BMI values in the three groups were compared to evaluate the relationship between snack energy intake and BMI, longitudinally. In addition, this study examined the relationship between the energy intake of snacks and the total energy and nutrient intake, including the meals.

\section{MATERIALS AND METHODS}

Subjects. This study protocol was approved by the Kindai University Faculty of Agriculture Life Ethics Committee (No. 2012-5) and was conducted in accordance with the Declaration of Helsinki. The recruited subjects were first graders in $2012(n=117 ; 71$ males and 46 females) and $2013(n=126 ; 76$ males and 50 females), respectively, at a private elementary school in Nara City. A baseline survey was conducted among the first graders (6-7-y-old) who consented to participate. A follow-up survey was conducted $4 \mathrm{y}$ after the baseline survey, when they were in the fifth grade (10-11-y-old). A total of 107 males (aged $10.2 \pm 0.05 \mathrm{y}$ ) and 82 females $(10.2 \pm 0.05 \mathrm{y})$ who were fifth graders in 2016 (50 males and 42 females) and 2017 (57 males and 40 females) and had completed all the surveys, were included in the analysis.

Anthropometric measurement. Data were obtained from the most recent anthropometric measurement records of the school's first and fifth graders on body weight $(\mathrm{kg})$ to the nearest $0.1 \mathrm{~kg}$ and standing height $(\mathrm{cm})$ to the nearest $0.1 \mathrm{~cm}$ while the children were wearing light clothes, in June of each school year.

Assessment index for obesity. BMI, a universal assessment index for the obesity level in children, was used in this study (19).

Assessment of snacking and habitual diets. For the snack intake habits, snack energy/nutrient intake per day was estimated using a self-administered snack-intake record obtained during 3 weekdays in the baseline survey and 2 weekdays in the follow-up. A snack was defined as any food or drink consumed by the children at times other than during breakfast, lunch, and dinner.
In both surveys, the guardians were instructed on how to complete the snack intake record at home for the types and amount of food in measured/estimated servings consumed by the children at times other than the mealtimes. These included snacks such as potato chips and chocolates, fruits, light meals, and nighttime snacks such as sweet bans, cup-noodles, and beverages. For commercial products, the guardians were instructed to record the names of the products and the amount of intake by referring to the weight indicated on the food label. For homemade products, they were instructed to record the type, recipe, and the amount of intake of the snacks. If the weight was unknown, they were asked to enter the standard serving size. The energy and nutrients of the snacks were calculated by using the nutrient value calculation software (Excel Eiyoukun ver. 7.0, Kenpakusha) and an ingredient list of processed foods in the market in Japan (8th edition) (20). The survey on the total energy and nutrient intake by habitual diets was conducted using a brief self-administered diet history questionnaire modified for school children (BDHQ$10 y)$ (21) in the follow-up. The BDHQ-10y was distributed to the children with a request to the parents or guardians to help provide the answers for the children. We excluded data of two subjects who reported extremely low or high total energy intake by BDHQ-10y (i.e., $<0.5$ times the estimated energy requirement value for the lowest physical activity category or $>1.5$ times that for the highest physical activity category, according to the dietary reference intakes for Japanese, issued in 2015) (22).

Questionnaire for exercise and sleep time. In the follow-up, subjects were asked to enter the total exercise hours per week (except for the class hours) and the average sleep hours per day on the lifestyle questionnaire sheet.

Statistical analysis. All statistical analyses were performed using the IBM SPSS Statistics for Windows, version 25.0 (IBM Corp., Armonk, N.Y., USA), and were separately performed for each sex. All the descriptive results were expressed as means and standard errors. The quantity of nutrient intake was evaluated as nutrient density, because adjusting for total energy intake is appropriate in epidemiologic studies to control for confounding factors (23). The Ministry of Agriculture, Forestry and Fisheries of Japan formulated the "Japanese Food Guide Spinning Top" (24) as a food guide. In this guide, since the amount of energy intake from snacks is recommended at $200 \mathrm{kcal} / \mathrm{d}$ or less for both adults and children, nutrient intake from snacks was indicated as nutrient density (per $200 \mathrm{kcal}$ ). Furthermore, the total amount of nutrient intake per day according to the BDHQ-10y was indicated as nutrient density (per $1,000 \mathrm{kcal})$. The paired $t$-test was used to compare the mean values in the baseline and follow-up survey. In order to analyze the longitudinal relationships of the snacks, the subjects were divided into three groups by tertiles (low, intermediate, and high groups), based on the energy intake of snacks in the baseline survey. Oneway analysis of variance (ANOVA) was used to compare 
Table 1. Basic characteristics of subjects and their snack and dietary intake.

Means (SE)

\begin{tabular}{|c|c|c|c|c|}
\hline & \multicolumn{2}{|c|}{ Males $(n=107)$} & \multicolumn{2}{|c|}{ Females $(n=82)$} \\
\hline & Baseline & Follow-up & Baseline & Follow-up \\
\hline Height $(\mathrm{cm})$ & $117.5(0.5)$ & $140.4(0.6)^{* * *}$ & $116.7(0.6)$ & $141.3(0.8)^{* * *}$ \\
\hline Weight (kg) & $21.3(0.3)$ & $34.4(0.6)^{* * *}$ & $20.9(0.3)$ & $34.2(0.8)^{* * *}$ \\
\hline BMI $\left(\mathrm{kg} / \mathrm{m}^{2}\right)$ & $15.4(0.1)$ & $17.4(0.2)^{* * *}$ & $15.3(0.2)$ & $17.0(0.3)^{* * *}$ \\
\hline Exercise (h/wk) & - & $3.2(0.4)$ & - & $1.8(0.2)$ \\
\hline Sleep time $(\mathrm{h} / \mathrm{d})$ & - & $7.7(0.1)$ & - & $7.8(0.1)$ \\
\hline \multicolumn{5}{|l|}{ (By snacking) } \\
\hline Energy (kcal) & $242(11)$ & $274(18)$ & $239(12)$ & $282(19)^{*}$ \\
\hline Snack/BDHQ energy ratio (\%) & - & $15.6(1.1)$ & - & $18.0(1.2)$ \\
\hline Protein $(\mathrm{g} / 200 \mathrm{kcal})$ & $5.7(0.7)$ & $4.2(0.3)^{*}$ & $4.9(0.8)$ & $3.9(0.2)$ \\
\hline Fat $(\mathrm{g} / 200 \mathrm{kcal})$ & $6.5(0.3)$ & $6.6(0.4)$ & $6.8(0.3)$ & $6.7(0.4)$ \\
\hline Carbohydrate (g/200 kcal) & $30.1(0.9)$ & $30.8(0.9)$ & $30.3(0.9)$ & $30.9(1.1)$ \\
\hline Calcium (mg/200 kcal) & $64.2(5.3)$ & $64.4(7.3)$ & $62.1(5.6)$ & $50.4(5.8)$ \\
\hline $\operatorname{Iron}(\mathrm{mg} / 200 \mathrm{kcal})$ & $0.42(0.04)$ & $0.32(0.03)^{*}$ & $0.42(0.04)$ & $0.31(0.04)$ \\
\hline Vitamin A ( $\mu \mathrm{gRAE} / 200 \mathrm{kcal})$ & $25.7(2.8)$ & $35.0(7.8)$ & $39.0(10.0)$ & $23.7(3.4)$ \\
\hline Vitamin $B_{1}(\mathrm{mg} / 200 \mathrm{kcal})$ & $0.06(0.00)$ & $0.06(0.01)$ & $0.05(0.00)$ & $0.07(0.02)$ \\
\hline Vitamin $\mathrm{B}_{2}(\mathrm{mg} / 200 \mathrm{kcal})$ & $0.11(0.01)$ & $0.10(0.01)$ & $0.13(0.03)$ & $0.10(0.02)$ \\
\hline Vitamin C (mg/200 kcal) & $13.4(2.4)$ & $18.5(7.8)$ & $12.1(2.6)$ & $11.1(2.7)$ \\
\hline Dietary fiber (g/200 kcal) & $0.81(0.07)$ & $0.94(0.13)$ & $0.69(0.06)$ & $0.62(0.07)$ \\
\hline Salt (g/200 kcal) & $0.29(0.02)$ & $0.40(0.04)^{*}$ & $0.27(0.02)$ & $0.40(0.04)^{* *}$ \\
\hline \multicolumn{5}{|l|}{ (By BDHQ) } \\
\hline Energy (kcal) & - & $1,887(48.8)$ & - & $1,579(38.9)$ \\
\hline Protein (g/1,000 kcal) & - & $36.8(0.6)$ & - & $37.3(0.5)$ \\
\hline Fat $(\mathrm{g} / 1,000 \mathrm{kcal})$ & - & $30.2(0.5)$ & - & $31.6(0.5)$ \\
\hline Carbohydrate (g/1,000 kcal) & - & $142.0(1.5)$ & - & $138.8(1.3)$ \\
\hline Calcium (mg/1,000 kcal) & - & $295.3(7.6)$ & - & $295.9(7.1)$ \\
\hline Iron $(\mathrm{mg} / 1,000 \mathrm{kcal})$ & - & $4.3(0.1)$ & - & $4.4(0.1)$ \\
\hline Vitamin A ( $\mu \mathrm{gRAE} / 1,000 \mathrm{kcal})$ & - & $365.8(13.7)$ & - & $390.1(14.5)$ \\
\hline Vitamin $\mathrm{B}_{1}(\mathrm{mg} / 1,000 \mathrm{kcal})$ & - & $0.45(0.01)$ & - & $0.47(0.01)$ \\
\hline Vitamin $\mathrm{B}_{2}(\mathrm{mg} / 1,000 \mathrm{kcal})$ & - & $0.74(0.01)$ & - & $0.77(0.01)$ \\
\hline Vitamin C (mg/1,000 kcal) & - & $78.2(2.6)$ & - & $89.4(2.8)$ \\
\hline Dietary fiber (g/1,000 kcal) & - & $6.7(0.2)$ & - & $7.1(0.2)$ \\
\hline Salt (g/1,000 kcal) & - & $5.5(0.1)$ & - & $5.7(0.1)$ \\
\hline
\end{tabular}

${ }^{*} p<0.05,{ }^{* *} p<0.01,{ }^{* * *} p<0.001 ;$ vs. baseline (paired $t$-test).

the mean values among the three groups, and the Jonckheere-Terpstra test was performed to verify the linear trend in the mean values of the three groups. Confounding factors that might affect BMI in the follow-up included BMI in the baseline, and exercise/sleep time. According to results of the test for parallelism and test for significance of regression coefficient of the covariate, BMI in the baseline was found to be the only confounding factor that required adjustment. One-way analysis of covariance (ANCOVA) (22) was used to evaluate differences in mean values adjusted for BMI in the baseline which affected BMI in the follow-up. Hence, the mean values of BMI in the follow-up after adjustment of the baseline BMI (adjusted BMI) were also tested for differences among the three groups, as well as the linear trend for the three groups, in the same manner. A $p<0.05$ was considered statistically significant.

\section{RESULTS}

Basic characteristics of the subjects and their snack and dietary intake

The basic characteristics and snack intake of subjects in the baseline and follow-up survey for both males and females, as well as the total energy and nutrient density in the follow-up are presented in Table 1. For males and females, the mean height in the baseline was $117.5 \mathrm{~cm}$ and $116.7 \mathrm{~cm}$, while the mean weight was $21.3 \mathrm{~kg}$ and $20.9 \mathrm{~kg}$, respectively. The mean heights in the follow-up were $140.4 \mathrm{~cm}$ and $141.3 \mathrm{~cm}$, while the mean weights were $34.4 \mathrm{~kg}$ and $34.2 \mathrm{~kg}$, respectively. For both males and females, a significant increase was observed in height, weight, and BMI in the follow-up than that in the baseline $(p<0.001)$. Energy intake from snacks increased significantly in females $(p<0.05)$ and appeared to increase in males in the follow-up than that in the baseline. Salt nutrient density derived from snacks also increased significantly in the follow-up than 
Table 2. Age, exercise, sleep time, BMI, snacks and dietary intake of subjects in the follow-up survey classified according to tertiles based on snack energy intake in the baseline survey. Means (SE)

\begin{tabular}{|c|c|c|c|c|c|c|c|c|}
\hline & \multicolumn{4}{|c|}{ Males $^{1}(n=107)$} & \multicolumn{4}{|c|}{ Females $^{2}(n=82)$} \\
\hline & $\begin{array}{l}\text { Low group } \\
(n=36)\end{array}$ & $\begin{array}{l}\text { Medium group } \\
\quad(n=36)\end{array}$ & $\begin{array}{l}\text { High group } \\
\quad(n=35)\end{array}$ & $\begin{array}{l}p \text { for } \\
\text { trend }\end{array}$ & $\begin{array}{l}\text { Low group } \\
\quad(n=28)\end{array}$ & $\begin{array}{l}\text { Medium group } \\
\quad(n=27)\end{array}$ & $\begin{array}{l}\text { High group } \\
\quad(n=27)\end{array}$ & $\begin{array}{l}p \text { for } \\
\text { trend }\end{array}$ \\
\hline Age in baseline & $6.4(0.1)$ & $6.3(0.1)$ & $6.1(0.1)$ & $0.016^{\#}$ & $6.2(0.1)$ & $6.2(0.1)$ & $6.2(0.1)$ & 0.947 \\
\hline Age in follow-up & $10.3(0.1)$ & $10.3(0.1)$ & $10.1(0.1)$ & $0.021^{\#}$ & $10.2(0.1)$ & $10.2(0.1)$ & $10.2(0.1)$ & 0.954 \\
\hline Exercise (h/wk) in follow-up & $3.8(0.6)$ & $3.2(0.7)$ & $2.7(0.4)$ & 0.097 & $1.8(0.3)$ & $1.6(0.3)$ & $2.1(0.5)$ & 0.433 \\
\hline Sleep time $(\mathrm{h} / \mathrm{d})$ in follow-up & $7.5(0.1)$ & $7.8(0.1)$ & $7.7(0.1)$ & 0.178 & $7.8(0.2)$ & $7.9(0.1)$ & $7.7(0.2)$ & 0.362 \\
\hline $\operatorname{BMI}\left(\mathrm{kg} / \mathrm{m}^{2}\right)$ in baseline & $15.3(0.2)$ & $15.2(0.3)$ & $15.6(0.2)$ & 0.587 & $15.2(0.4)$ & $15.2(0.2)$ & $15.6(0.3)$ & 0.220 \\
\hline BMI $\left(\mathrm{kg} / \mathrm{m}^{2}\right)$ in follow-up & $17.6(0.4)$ & $16.9(0.3)$ & $17.6(0.3)$ & 0.819 & $16.7(0.5)$ & $16.7(0.4)$ & $17.8(0.6)$ & 0.112 \\
\hline Adjusted $\mathrm{BMI}^{3}$ & $17.7(0.3)$ & $17.1(0.3)$ & $17.3(0.3)$ & 0.560 & $16.9(0.3)$ & $16.8(0.3)$ & $17.4(0.3)$ & $0.033^{\#}$ \\
\hline Energy (kcal) & $236(28)$ & $262(31)$ & $325(32)$ & $0.033^{\#}$ & $196(25)$ & $335(35)^{* *}$ & $318(32)^{*}$ & $0.005^{\# \#}$ \\
\hline Snack/BDHQ energy ratio (\%) & $12.8(1.6)$ & $15.8(2.1)$ & $18.2(2.1)$ & $0.039^{\#}$ & $12.6(1.7)$ & $21.3(2.1)^{* *}$ & $20.3(1.9)^{*}$ & $0.006^{\# \#}$ \\
\hline Protein $(\mathrm{g} / 200 \mathrm{kcal})$ & $4.3(0.5)$ & $4.1(0.4)$ & $4.2(0.5)$ & 0.902 & $3.5(0.4)$ & $3.5(0.3)$ & $4.6(0.4)$ & $0.038^{\#}$ \\
\hline Fat $(\mathrm{g} / 200 \mathrm{kcal})$ & $6.6(0.7)$ & $7.2(0.7)$ & $6.3(0.6)$ & 0.661 & $6.1(0.8)$ & $7.5(0.9)$ & $6.6(0.6)$ & 0.592 \\
\hline Carbohydrate (g/200 kcal) & $30.8(1.6)$ & $29.6(1.6)$ & $31.6(1.4)$ & 0.648 & $32.5(1.9)$ & $29.4(2.1)$ & $30.6(1.6)$ & 0.477 \\
\hline Calcium (mg/200 kcal) & $55.9(11.1)$ & $78.8(15.1)$ & $58.3(11.2)$ & 0.855 & $46.5(9.8)$ & $36.7(6.7)$ & $68.2(12.4)$ & 0.138 \\
\hline Iron $(\mathrm{mg} / 200 \mathrm{kcal})$ & $0.32(0.06)$ & $0.32(0.05)$ & $0.33(0.05)$ & 0.679 & $0.29(0.05)$ & $0.23(0.03)$ & $0.40(0.10)$ & 0.685 \\
\hline Vitamin A ( $\mu \mathrm{gRAE} / 200 \mathrm{kcal})$ & $40.2(17.8)$ & $43.0(14.0)$ & $21.6(5.1)$ & 0.646 & $23.2(4.8)$ & $20.2(6.5)$ & $27.8(6.3)$ & 0.622 \\
\hline Vitamin $B_{1}(\mathrm{mg} / 200 \mathrm{kcal})$ & $0.05(0.01)$ & $0.05(0.01)$ & $0.08(0.02)$ & 0.482 & $0.12(0.06)$ & $0.04(0.01)$ & $0.06(0.01)$ & 0.083 \\
\hline Vitamin $B_{2}(\mathrm{mg} / 200 \mathrm{kcal})$ & $0.07(0.01)$ & $0.12(0.02)$ & $0.11(0.03)$ & 0.523 & $0.14(0.05)$ & $0.06(0.01)$ & $0.08(0.02)$ & 0.704 \\
\hline Vitamin C (mg/200 kcal) & $12.7(5.5)$ & $5.5(1.2)$ & $37.8(23.1)$ & 0.498 & $14.1(5.5)$ & $4.5(1.4)$ & $14.5(5.8)$ & 0.393 \\
\hline Dietary fiber (g/200 kcal) & $1.14(0.30)$ & $0.77(0.13)$ & $0.91(0.24)$ & 0.718 & $0.52(0.12)$ & $0.58(0.11)$ & $0.75(0.14)$ & 0.120 \\
\hline Salt (g/200 kcal) & $0.48(0.10)$ & $0.36(0.04)$ & $0.35(0.04)$ & 0.835 & $0.32(0.07)$ & $0.40(0.05)$ & $0.48(0.08)$ & $0.013^{\#}$ \\
\hline \multicolumn{9}{|l|}{ (BDHQ in follow-up) } \\
\hline Energy (kcal) & $1,917(86)$ & $1,831(91)$ & $1,915(78)$ & 0.936 & $1,568(67)$ & $1,570(60)$ & $1,601(76)$ & 0.680 \\
\hline Protein $(\mathrm{g} / 1,000 \mathrm{kcal})$ & $36.7(1.1)$ & $36.6(1.0)$ & $37.1(0.8)$ & 0.552 & $38.7(0.9)$ & $36.8(1.0)$ & $36.4(0.9)$ & 0.101 \\
\hline Fat $(\mathrm{g} / 1,000 \mathrm{kcal})$ & $29.1(0.8)$ & $29.7(0.9)$ & $31.8(0.9)$ & $0.030^{\#}$ & $31.3(0.8)$ & $32.9(0.9)$ & $30.5(0.8)$ & 0.554 \\
\hline Carbohydrate (g/1,000 kcal) & $144.5(2.5)$ & $143.1(2.7)$ & $138.2(2.3)$ & 0.111 & $138.2(2.0)$ & $136.3(2.4)$ & $141.8(2.2)$ & 0.289 \\
\hline Calcium (mg/1,000 kcal) & $280.3(12.3)$ & $300.1(14.5)$ & $305.8(12.2)$ & 0.114 & $306.7(11.0)$ & $305.3(11.8)$ & $275.3(13.6)$ & $0.018^{\#}$ \\
\hline Iron $(\mathrm{mg} / 1,000 \mathrm{kcal})$ & $4.2(0.2)$ & $4.3(0.1)$ & $4.3(0.1)$ & 0.354 & $4.6(0.2)$ & $4.4(0.1)$ & $4.3(0.1)$ & 0.215 \\
\hline Vitamin A ( $\mu \mathrm{gRAE} / 1,000 \mathrm{kcal})$ & $353.0(25.2)$ & $388.5(27.2)$ & $355.7(17.7)$ & 0.522 & $420.0(16.0)$ & $361.9(20.2)$ & $387.3(35.2)$ & $0.013^{\#}$ \\
\hline Vitamin $B_{1}(\mathrm{mg} / 1,000 \mathrm{kcal})$ & $0.45(0.02)$ & $0.44(0.01)$ & $0.46(0.01)$ & 0.941 & $0.48(0.01)$ & $0.46(0.01)$ & $0.46(0.01)$ & 0.235 \\
\hline Vitamin $B_{2}(\mathrm{mg} / 1,000 \mathrm{kcal})$ & $0.72(0.03)$ & $0.74(0.03)$ & $0.77(0.03)$ & 0.101 & $0.79(0.02)$ & $0.76(0.03)$ & $0.75(0.03)$ & 0.252 \\
\hline Vitamin C (mg/1,000 kcal) & $80.9(5.9)$ & $76.1(3.8)$ & $77.7(3.6)$ & 0.936 & $94.9(5.6)$ & $86.7(4.4)$ & $86.3(4.7)$ & 0.313 \\
\hline Dietary fiber (g/1,000 kcal) & $6.9(0.4)$ & $6.6(0.2)$ & $6.6(0.2)$ & 0.909 & $7.5(0.3)$ & $7.1(0.3)$ & $6.7(0.2)$ & 0.052 \\
\hline Salt (g/1,000 kcal) & $5.3(0.2)$ & $5.6(0.2)$ & $5.5(0.2)$ & 0.567 & $5.8(0.2)$ & $5.6(0.2)$ & $5.6(0.2)$ & 0.705 \\
\hline
\end{tabular}

Classification of subjects by tertiles based on snack energy intake in the baseline survey.

${ }^{1}$ Males: low $(<193 \mathrm{kcal} / \mathrm{d})$, intermediate $(\geq 193 \mathrm{kcal}$ and $<289 \mathrm{kcal})$, and high $(\geq 289 \mathrm{kcal})$.

${ }^{2}$ Females: low $(<195 \mathrm{kcal} / \mathrm{d})$, intermediate $(\geq 195 \mathrm{kcal}$ and $<264 \mathrm{kcal})$, and high $(\geq 264 \mathrm{kcal})$.

${ }^{3}$ The mean values of BMI in the follow-up survey after adjustment of the baseline BMI.

ANCOVA (22) was used to evaluate differences in mean values adjusted for BMI in the baseline which affected BMI in the follow-up.

${ }^{*} p<0.05,{ }^{* *} p<0.01$; vs. low (ANOVA, Bonferroni).

${ }^{\#} p<0.05,{ }^{\# \#} p<0.01$; trend (Jonckheere-Terpstra test).

that in the baseline for both male $(p<0.05)$ and female $(p<0.01)$ subjects. Nutrient density for both protein and iron decreased significantly in the follow-up than that in the baseline for the male subjects $(p<0.05)$, and also appeared to decrease in female subjects. The percentage of energy intake from snacks in the follow-up was $15.6 \%$ in male subjects and $18.0 \%$ in female subjects.

Classification of the subjects by tertiles of snack energy intake in baseline survey

According to the tertiles of the snack energy intake in the baseline survey, male subjects were divided into the following three groups: low $(<193 \mathrm{kcal} / \mathrm{d})$, intermediate $(\geq 193 \mathrm{kcal}$ and $<289 \mathrm{kcal})$, and high $(\geq 289$ kcal) groups. Likewise, for the female subjects, these were: low $(<195 \mathrm{kcal} / \mathrm{d})$, intermediate $(\geq 195 \mathrm{kcal}$ and $<264 \mathrm{kcal})$, and high ( $\geq 264 \mathrm{kcal})$ groups.

Lifestyle, BMI, snacks, and dietary intake of the subjects in follow-up survey

Age, exercise/sleep time, BMI, snacks, and dietary intake of subjects in the follow-up survey, who were categorized into three groups based on the tertiles of snack energy intake in the baseline survey are presented in Table 2. No significant differences were observed among the three groups for both males and females with respect to age, exercise/sleep time, BMI in the baseline and follow-up, and the adjusted BMI. However, a significantly positive linear trend $(p<0.05)$ was observed for 
the adjusted BMI in females, among the three groups. A significantly negative linear trend for age was observed among the 3 groups in male subjects $(p<0.05)$, but this was not clinically meaningful because the subjects were all aged 10 or $11 \mathrm{y}$ in the follow-up.

Snack intake in follow-up survey

Energy intake from snacks in the follow-up survey was significantly higher in the intermediate $(p<0.01)$ and high $(p<0.05)$ groups, than that in the low group, and a significantly positive linear trend was also found among the 3 groups $(p<0.01)$ in female subjects. In male subjects, no significant difference was observed; but, a significantly positive trend was observed among the 3 groups $(p<0.05)$. The difference among the three groups in the percentage of snack energy intake in the total energy intake per day, estimated with BDHQ-10y (Snack/BDHQ energy ratio (\%)), was similar to the results for the snack energy intake. No significant difference was observed in all the nutrient densities of snack intake in the follow-up among the three groups for both male and female subjects. However, there was a significantly positive linear trend $(p<0.05)$ in protein and salt nutrient density among the 3 groups in female subjects. Dietary intake in follow-up survey

There was no significant difference observed in total energy intake per day and in all the nutrient densities, estimated with BDHQ-10y, among the three groups for both male and female subjects. However, there was a significantly positive linear trend $(p<0.05)$ in the fat nutrient density among the three groups in male subjects. In female subjects, a significantly negative linear trend $(p<0.05)$ was found in calcium and vitamin A nutrient density among the 3 groups, and a borderline significant $(p=0.052)$ negative linear trend was observed in dietary fiber.

\section{DISCUSSION}

There is no consistency in the results of previous studies that investigated the relationship between snacking and obesity in children. Many of the studies were cross-sectional, and often focused only on the frequency rather than the amount of snack intake, and in interventional studies, it is difficult to intervene with children. Therefore, we conducted a longitudinal study on the amount of snack intake based on a snack intake record survey.

At baseline, the subjects in this study were first graders in an elementary school. The effects of snacking on their bodies were assessed in a follow-up survey $4 \mathrm{y}$ after the baseline survey. The dietary habits in children gradually become similar to those of adults, as they develop from infancy. The first year in an elementary school is the time for children to have meals similar to those of adults (25). Children's speed of physical development between the first and fifth grades is more stable than that during infancy and puberty; however, the percentages of obese and lean children increase during this period (26). Thus, the subjects in this study were considered appropriate for the longitudinal investigation of the relationship between snacking and BMI during the growth period.

In this study, the investigation was conducted in elementary school children in Japan, a country with low obesity rate (27). According to the Japanese School Health Statistics Survey Report 2013 (26), the mean heights of 6 -y-old males and females were $116.6 \mathrm{~cm}$ and $115.6 \mathrm{~cm}$, while the mean weights were $21.3 \mathrm{~kg}$ and $20.9 \mathrm{~kg}$, respectively. It is presumed that their mean heights and weights are similar to that of children in an average elementary school in Japan.

Among the three female groups of snack energy intake in the baseline, there was no significant difference in the mean BMI value in the follow-up and adjusted BMI. However, in the adjusted BMI, a significantly positive linear trend was observed among the three groups. This indicates that, although the influence of snacking on BMI is not very prominent, there is a positive association between snack energy intake and BMI in female subjects. On the other hand, no such correlation was observed between snack energy intake and BMI in the male subjects.

In a similar longitudinal study, conducted by Field et al., a 3-y follow-up investigation was conducted in children aged 9-14 y in the United States. They reported that there was no association between snacking (serving size) and weight change in both males and females (28). In their study, they used a questionnaire to obtain information on the frequency of dietary intake, which included question items on 25 types of snacks, including potato chips and doughnuts. The present study was conducted using a self-administered recording method, with the definition of snacks including all kinds of food and drinks consumed at times other than during the three main meals. These included light meals, such as rice balls, cup noodles, and beverages. In the United States study, sweetened drinks such as sodas were not included in the snacks. However, in another longitudinal study conducted in 8-12-y-old female subjects, a positive association was reported between the amount of soda intake alone and BMI (15). The present study differs from these previous studies in that a wide range of drinks, including sodas, were also considered as snacks. Moreover, in the present study, energy was calculated and assessed with a recording method including the weight of snacks, while in the previous studies, the amount of snack intake was assessed with the serving size. Hence, differences in the definition of snacks or in the assessment methods may have contributed to the discrepancy between the results.

Larson et al. conducted a cross-sectional study, focusing on the energy density of snacks, and reported that intake of low energy-density snacks was inversely correlated with BMI (29). Furthermore, O'Connor et al. reported that adults with a normal weight often select yogurt or nuts as their snacks, while obese adults tend to snack on high energy density foods such as ice cream and cakes (30). In the present study, a focus was placed on the amount of energy in the snacks. However, in the future, further analyses should be performed taking into consideration the quality of snacks, such as the 
energy density of the snacks and the types of nutrients contained in the snacks.

This study indicated an association between snacks and BMI only in female subjects. One of the reasons for this may be that the percentage of snack-derived energy was greater than $20 \%$ in the intermediate and high groups, and it was likely to be higher than that in male subjects. In addition, females reach sexual maturity approximately $2 \mathrm{y}$ earlier than males, and the physical development rate would be the highest at $9 \mathrm{y}$ of age (26). The female subjects aged 10-11 y (fifth grade), who just passed the developmental peak, were likely to manifest the influence of snacking more prominently than males. Thus, further investigations are necessary on this difference between males and females.

In the present study, it was suggested that the amount of snack energy intake increased in both males and females along with their growth. In addition, for the three groups classified according to the amount of snack energy intake in the baseline (first grade), there was no clear difference between the intermediate and high groups in the follow-up (fifth grade); while those who had a low snack energy intake in the baseline survey, had a persistently low snack energy intake in the follow-up. These findings suggest that the snacking habits during elementary school years would persist in general.

The total energy intake did not change regardless of snack energy intake per day in either the male or female subjects. Children with high snack intake may have lost their appetite after snacking, resulting in a reduced dietary intake during the three regular meals; thereby showing no difference in the total energy intake per day. In this regard, Leidy and Campbell reported that adults who frequently eat snacks would lose their appetite, resulting in reduced dietary intake at meals, followed by weight loss (31). However, Taillie et al. indicated that in children aged 6-13y, an increase in frequency of snacking would result in excessive total energy intake per day (32).

Furthermore, there was an association between snacking and the quality of meals (nutrient density). In male subjects, a positive linear trend was observed between snack energy intake and fat nutrient density per day. In female subjects, there was a negative linear trend between daily snack energy intake and nutrient density for calcium, vitamin A, and dietary fiber. It was considered, particularly in females, that excessive snack intake may have resulted in the suppression of the dietary intake of vitamins, minerals, and dietary fiber from meals.

Several limitations of this study should be acknowledged. The total dietary constituent per day in the follow-up was estimated using the BDHQ-10y. However, its accuracy in absolute values was lesser than that obtained by the recording method, which listed what was actually consumed. Nonetheless, Okuda et al. reported that there was a certain level of validity in the BDHQ-10y using biomarkers (33). As there was no survey conducted on meals using BDHQ-10y at baseline, longitudinal changes in the total energy and nutrient intake per day were unclear. The snack intake record survey was conducted for $3 \mathrm{~d}$ in the baseline, and the duration of the survey was shortened to $2 \mathrm{~d}$ in the follow-up. This might have contributed to errors associated with day-to-day variations. The duration of the survey was shortened in the follow-up in order to avoid a decrease in accuracy due to excessive burdens on the subjects (guardians) who were asked to complete the BDHQ-10y. Caution is required to interpret the results because the size of the study population was relatively small, and significant differences and linear trends were observed among the three groups only. We investigated exercise time and sleep time as factors that may affect BMI, but could not cover all the confounding factors.

However, there were also advantages with this study: gender analyses were performed, the mean heights and weights of the study population were approximately the same as that of the national average (26), and the percentage of subjects who completed the 4-y follow-up survey was relatively high.

In conclusion, there was a positive linear trend between snack energy intake and BMI in female subjects, although the influence of snack energy intake on BMI was not very prominent. However, there was no such association observed in male subjects. The association between snack energy intake and meal quality was observed in both male and female subjects. Particularly in females, there was a decreased tendency of the nutrient density of calcium, vitamin A, and dietary fiber as the amount of snack energy intake increased. Nevertheless, further investigations are required to determine the ideal snacking habits in children, taking into consideration the quality and timing of the snack intake.

\section{Authorship}

Research conception and design: TK; experiments and data collection: TK, AS, TS, KR, NI, CM and MK; statistical analysis of the data: TK and HT; interpretation of the data: TK and AS; writing of the manuscript: TK and AS.

\section{Disclosure of state of COI}

No conflicts of interest to be declared.

\section{Acknowledgments}

We would like to thank all the students who participated in this study and Editage (www.editage.com) for the English language editing of the manuscript.

\section{REFERENCES}

1) Takeichi H, Taniguchi H, Fukinbara M, Tanaka N, Shikanai S, Sarukura N, Hsu TF, Wong Y, Yamamoto S. 2012. Sugar intakes from snacks and beverages in Japanese children. J Nutr Sci Vitaminol 58: 113-117.

2) Johnson GH, Anderson GH. 2010. Snacking definitions: impact on interpretation of the literature and dietary recommendations. Crit Rev Food Sci Nutr 50: 848-871.

3) Mercille G, Receveur O, Macaulay AC. 2010. Are snacking patterns associated with risk of overweight among Kahnawake schoolchildren?. Public Health Nutr 13: 
163-171.

4) Mikkilä V , Räsänen L, Raitakari OT, Pietinen P, Viikari J. 2004. Longitudinal changes in diet from childhood into adulthood with respect to risk of cardiovascular diseases: The Cardiovascular Risk in Young Finns Study. Eur J Clin Nutr 58: 1038-1045.

5) Ward ZJ, Long MW, Resch SC, Giles CM, Cradock AL, Gortmaker SL. 2017. Simulation of growth trajectories of childhood obesity into adulthood. N Engl J Med 377: 2145-2153.

6) Dunford E, Popkin B. 2018. 37 year snacking trends for US children 1977-2014. Pediatr Obes 13: 247-255.

7) Adair LS, Popkin BM. 2005. Are child eating patterns being transformed globally?. Obes Res 13: 1281-1299.

8) Murakami K, Livingstone. MBE. 2016. Associations between meal and snack frequency and overweight and abdominal obesity in US children and adolescents from National Health and Nutrition Examination Survey (NHANES) 2003-2012. Br J Nutr 115: 1819-1829.

9) Kachurak A, Davey A, Bailey RL, Fisher JO. 2018. Daily snacking occasions and weight status among US children aged 1 to 5 years. Obesity 26: 1034-1042.

10) Tripicchio GL, Kachurak A, Davey A, Bailey RL, Dabritz LJ, Fisher JO. 2019. Associations between snacking and weight status among adolescents 12-19 years in the United States. Nutrients 11: 1486.

11) Vatanparast H, Islam N, Patil RP, Shafiee M, Smith J, Whiting S. 2019. Snack consumption patterns among Canadians. Nutrients 11: 1152.

12) Keast DR, Nicklas TA, O'Neil CE. 2010. Snacking is associated with reduced risk of overweight and reduced abdominal obesity in adolescents: National Health and Nutrition Examination Survey (NHANES) 1999-2004. Am J Clin Nutr 92: 428-435.

13) House BT, Shearrer GE, Miller SJ, Pasch KE, Goran MI, Davis JN. 2015. Increased eating frequency linked to decreased obesity and improved metabolic outcomes. Int J Obes 39: 136-141.

14) Njike VY, Smith TM, Shuval O, Shuval K, Edshteyn I, Kalantari V, Yaroch AL. 2016. Snack food, satiety, and weight. Adv Nutr 7: 866-878.

15) Phillips SM, Bandini LG, Naumova EN, Cyr H, Colclough S, Dietz WH, Must A. 2004. Energy-dense snack food intake in adolescence: Longitudinal relationship to weight and fatness. Obes Res 12: 461-472.

16) Taillie LS, Wang D, Popkin BM. 2016. Snacking is longitudinally associated with declines in body mass index $\mathrm{Z}$ scores for overweight children, but increases for underweight children. J Nutr 146: 1268-1275.

17) Hess JM, Jonnalagadda SS, Slavin JL. 2016. What is a snack, why do we snack, and how can we choose better snacks? A review of the definitions of snacking, motivations to snack, contributions to dietary intake, and recommendations for improvement. Adv Nutr 7: 466-475.

18) Potter M, Vlassopoulos A, Lehmann U. 2018. Snacking recommendations worldwide: A scoping review. Adv Nutr 9: 86-98.

19) de Onis M, Onyango AW, Borghi E, Siyam A, Nishida C, Siekmann J. 2007. Development of a WHO growth ref- erence for school-aged children and adolescents. Bull World Health Organ 85: 660-667.

20) Kohri T, Kaba N. 2015. Impact of snack choice education on first grader's snack intake at home. The Journal of Japan Mibyou System Association 21: 65-71.

21) Kohri T, Kaba N, Murakami T, Narukawa T, Yamamoto S, Sakai T, Sasaki S. 2012. Search for promotion factors of ultrasound bone measurement in Japanese males and pre/post-menarcheal females aged 8-14 years. $J$ Nutr Sci Vitaminol 58: 263-271.

22) Kohri T, Kaba N, Itoh T, Sasaki S. 2016. Effects of the national school lunch program on bone growth in Japanese elementary school children. J Nutr Sci Vitaminol 62: 303-309.

23) Willett WC, Howe GR, Kushi LH. 1997. Adjustment for total energy intake in epidemiologic studies. Am J Clin Nutr 65 (4 Suppl): 1220S-1228S.

24) Takaizumi K. 2010. Dissemination strategy of Japanese Food Guide Spinning Top by the Ministry of Agriculture, Forestry and Fisheries. Journal of Japan Society of Sports Industry 20: 139-142 (in Japanese).

25) Pearson N, Biddle SJH, Gorely T. 2008. Family correlates of fruit and vegetable consumption in children and adolescents: a systematic review. Public Health Nutr 12: 267-283.

26) Ministry of Education, Culture, Sports, Science and Technology. 2013. School Health Statistics Survey Report 2013, p 5-10. Nikkei Printing Inc, Tokyo.

27) Chung A, Backholer K, Wong E, Palermo C, Keating C, Peeters A. 2016. Trends in child and adolescent obesity prevalence in economically advanced countries according to socioeconomic position: a systematic review. Obes Rev 17: 276-295.

28) Field AE, Austin SB, Gillman MW, Rosner B, Rockett HR, Colditz GA. 2004. Snack food intake does not predict weight change among children and adolescents. Int J Obes Relat Metab Disord 28: 1210-1216.

29) Larson NI, Miller JM, Watts AW, Story MT, NeumarkSztainer DR. 2016. Adolescent snacking behaviors are associated with dietary intake and weight status. J Nutr 146: 1348-1355.

30) O'Connor L, Brage S, Griffin SJ, Wareham NJ, Forouhi NG. 2015. The cross-sectional association between snacking behaviour and measures of adiposity: the Fenland Study, UK. Br J Nutr 114: 1286-1293.

31) Leidy HJ, Campbell WW. 2011. The effect of eating frequency on appetite control and food intake: Brief synopsis of controlled feeding studies. J Nutr 141: 154S-157S.

32) Taillie LS, Afeiche MC, Eldridge AL, Popkin BM. 2015. Increased snacking and eating occasions are associated with higher energy intake among Mexican children aged 2-13 years. J Nutr 145: 2570-2577.

33) Okuda M, Sasaki S, Bando N, Hashimoto M, Kunitsugu I, Sugiyama S, Terao J, Hobara T. 2009. Carotenoid, tocopherol, and fatty acid biomarkers and dietary intake estimated by using a brief self-administered diet history questionnaire for older Japanese children and adolescents. J Nutr Sci Vitaminol 55: 231-241. 